\title{
Periductal mastitis and mammary duct ectasia in a male
}

\author{
M.T. Ashworth, G.D. Corcoran and M.T. Haqqani
}

Walton Hospital, Liverpool L9 1AE, UK.

\begin{abstract}
Summary: A case of periductal mastitis and mammary duct ectasia is presented in a 50 year old male, with presenting symptoms similar to those of females, namely subareolar breast lump and mastalgia. As far as can be ascertained only $\mathbf{4}$ cases of mammary duct ectasia and periductal mastitis in males have been reported previously. Since this entity is not well known in males it is possible that it may be underdiagnosed or misdiagnosed clinically and histologically.
\end{abstract}

\section{Case report}

A 50 year old man presented in 1983 with a 2 month history of a small lump beneath the right nipple. The swelling had enlarged gradually and caused an aching discomfort without nipple discharge. There was no history of trauma and no medications were being taken.

On examination the left breast was normal. In the right breast there was a well defined, ovoid, subareolar mass which was attached to the underlying muscle and also to the skin, which was erythematous. The nipple was normal and there was no lymphadenopathy. Full blood count, liver function tests and chest X-ray were normal. A xerogram was reported as showing bilateral gynaecomastia without microcalcification and marked tethering and oedema of the skin adjacent to the right nipple with probable abscess formation underneath.

The patient underwent a major duct excision beneath the right nipple via a sub-mammary incision and subsequently made an uneventful recovery.

\section{Pathology}

The excised specimen consisted of a piece of fibro-fatty tissue measuring $4.0 \times 3.5 \times 3.0 \mathrm{~cm}$ containing a firm, white, poorly circumscribed nodule measuring $2.0 \times 1.0 \times 1.0 \mathrm{~cm}$. On microscopic examination the tissue was composed of breast ducts in a dense fibrous stroma with some adipose tissue. There was a variable periductal infiltrate of plasma cells and lymphocytes, ranging from scattered cells to dense collections, and occasional non-caseating granulomas (Figure 1). The

Correspondence: M.T. Haqqani, M.B., B.S., D.Path., M.R.C.Path.

Accepted: 30 October 1984

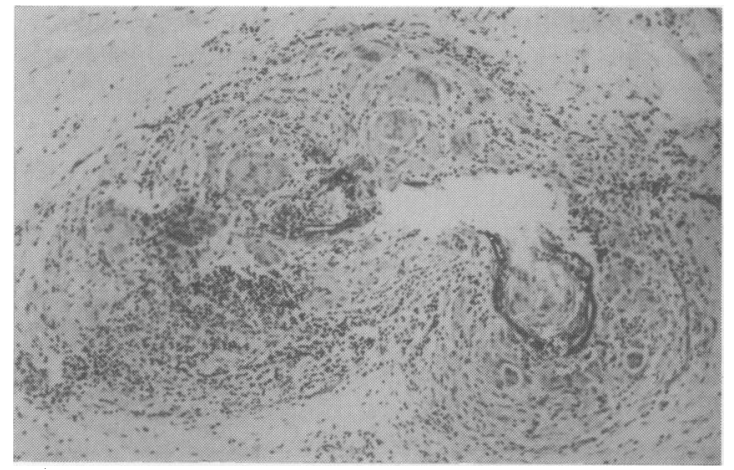

Figure 1 Mammary duct with broken epithelial lining surrounded by a heavy lymphocytic and plasma cell infiltrate, and several multinucleated foreign body giant cells. H \& $\mathrm{E} \times 250$.

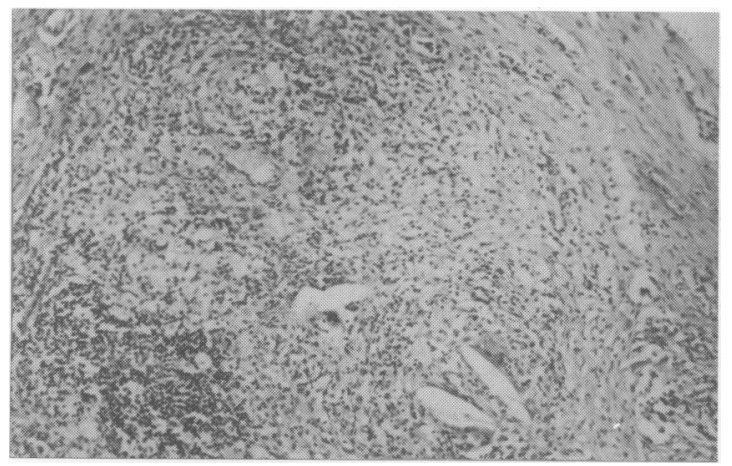

Figure 2 The duct is distended and its architecture is obscured due to a heavy cellular infiltrate containing numerous foamy macrophages and clefts surrounded by multinucleated giant cells. H \& $\mathrm{E} \times 250$.

(C) The Fellowship of Postgraduate Medicine, 1985 


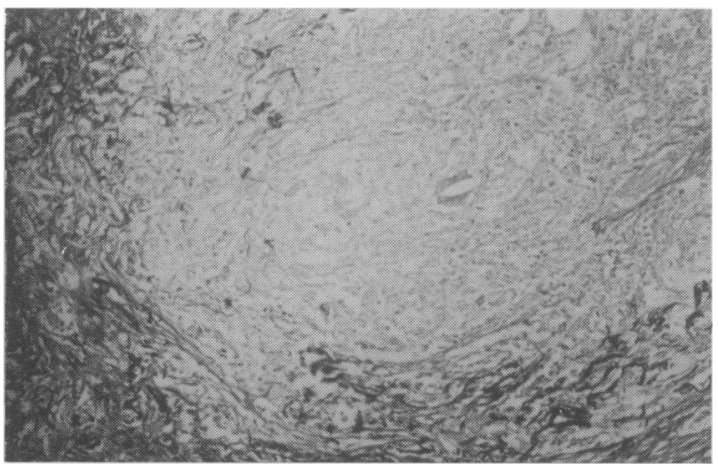

Figure 3 Same area as Figure 2, showing condensed elastic fibres outlining the remnants of the ductal architecture. Miller's elastic Van Gieson stain $\times 250$.

duct architecture was obscured due to heavy cellular infiltration (Figure 2). There were plasma cells, lymphocytes, histiocytes and numerous 'foam cells' both within the duct lumina and in the surrounding tissue. In places there were needle-shaped clefts surrounded by multinucleated foreign body giant cells, apparently within ducts. In the areas of dense inflammatory cell infiltration the obscured and obliterated ductal architecture could be outlined with stains for elastic tissue (Figure 3). The remnants of elastic fibres were seen around damaged and dilated ducts. In other areas there were intact ducts surrounded by moderate to heavy plasma cell and lymphocytic infiltration suggestive of widespread periductal mastitis. Dense interstitial fibrosis with fibrous replacement of the ducts was also noticed. No microcalcification was seen and there was no evidence of carcinoma or gynaecomastia.

\section{Discussion}

The term mammary duct ectasia was first introduced by Haagensen in 1951. Since then mammary duct ectasia (periductal mastitis) has become a well recognized clinical (Thomas et al., 1982) and pathological (Azzopardi, 1979) entity in the female breast. To the best of our knowledge only four cases of mammary duct ectasia in the male breast have been previously reported (Tedeschi \& McCarthy, 1974; Mansel \&

\section{References}

ANDERSEN, J.A. \& GRAM, J.B. (1982). Male breast at autopsy. Acta Pathologica et Microbiologica Scandinavica, 90, 191.

AZZOPARDI, J.G. (1979). In Problems in Breast Pathology, p. 72-87. Saunders: London.

BONSER, G.M., DOSSETT, J.A. \& JULL, J.N. (1961). In Human
Morgan, 1979). In a survey of 100 male necropsies by Andersen \& Gram (1982) ectasia of mammary ducts was found in $30 \%$ of cases. However, no clinical symptoms were related to the lesions and the authors concluded that the histological picture was quantitatively and qualitatively different from that seen in the female breast and was unlikely to have the same aetiology.

In the case described here the clinical presentation and florid inflammatory picture is similar to that seen in the female breast and corresponds to the description of Dixon et al. (1983) of the form of the disease occurring in younger patients, namely, florid inflammation with relatively few dilated ducts. The age group of our case is similar to the previously reported cases but the clinical presentation of a tender juxtaareolar lump is closer to the case described by Tedeschi \& McCarthy (1974) than to the recurrent abscesses described by Mansel \& Morgan (1979). An interesting point is that the xerogram in our case was reported as showing gynaecomastia, thus supporting the assertion that the appearances of severe periductal mastitis and gynaecomastia are indistinguishable on mammography (Mansel \& Morgan, 1979).

According to recent studies on female mammary duct ectasia (Azzopardi, 1979; Dixon et al., 1983) the sequence of events in the development of the lesion appear to be periductal inflammation followed by resolution of the inflammatory reaction, periductal fibrosis and finally ductal dilatation. In the study of the present case the same sequence of events is likely to occur in the male breast. We entirely agree with other workers that periductal mastitis is a more appropriate term for this condition.

In the female breast, pregnancy and lactation have been proposed as aetiological factors in duct ectasia (Bonser, et al., 1961), although this view has recently been challenged (Dixon et al., 1983). Lactation is extremely unlikely to be an aetiological factor in males despite an interesting anecdotal case of gynaecomastia in a 70 year old man cited by Tedeschi \& McCarthy (1974). An autoimmune reaction as seen in experimental animals (Davies, 1972) may account for the inflammatory changes. Obviously, further study of male duct ectasia (periductal mastitis) is needed to make any meaningful comparison with its female counterpart, particularly with regard to its aetiology.

and Experimental Breast Cancer, p. 237-65. Pitman Medical: London.

DAVIES, J.D. (1972). Histological study of mammae in oestrogenized rats after mammary isoimmunization. British Journal of Experimental Pathology, 53, 406.

DIXON, J.M., ANDERSON, T.J., LUMSDEN, A.B., ELTON, 
R.A., ROBERTS, M.M. \& FORREST, A.P.M. (1983). Mammary duct ectasia. British Journal of Surgery, 70, 601.

HAAGENSEN, C.D. (1951). Mammary duct ectasia: a disease that may simulate carcinoma. Cancer, 4, 749.

MANSEL, R.E. \& MORGAN, W.P. (1979). Duct ectasia in the male. British Journal of Surgery, 66, 660.
TEDESCHI, I.G. \& McCARTHY, P.E. (1974). Involutional mammary duct ectasia and periductal mastitis in a male. Human Pathology, 5, 232.

THOMAS, W.G. WILLIAMSON, R.C.N., DAVIES, J.D. \& WEBB, A.J. (1982). The clinical syndrome of mammary duct ectasia. British Journal of Surgery, 69, 423. 